\title{
LOS ULTIMOS DIAS DE JORGE LUIS BORGES
}

\author{
Miguelina Solfer \\ Universidade Federal do Paraná
}

\section{RESUMO}

Comenta-se a crônica de Angelo Rinaldi que a revista L'Express publicou ao noticiar a morte de Jorge Luis Borges, como exemplo de excelència jornalistica, ao denunciar juizos ambiguos e infundados, forjados em torno da figura de Borges, e traçando o retrato espiritual deste gênio do século XX.

"La literatura vuelve una página magistral de su gran libro", anuncia en significativa frase el Sumario de la revista. Entre las innumerables crónicas dedicadas por la prensa mundial a evocar la personalidad genial de Jorge Luis Borges el articulo escrito por Angelo RINALDI para la revista L'EXPRESS*, pocos días después de la muerte del escritor argentino, se destaca como ejemplo de excelencia periodística reflejando el espíritu de acuidad intelectual y sentido humanista que sólo florece en suelos favorables a la libertad de ideas y a la amplia comprensión del fenómeno humano, suelos impermeables a constricciones sectarias $y$ a toda estrechez en la visión del mundo. A partir del plano anecdó. tico de los últimos días que precedieron al eclipse final del sol borgesiano, el cronista consigue recrear con unas magistrales pinceladas, las dimensiones múltiples y verdaderas de la personalidad que retrata, proyectándola sobre la visión del universo social, político, cultural y humano que Borges y sus lectores habitamos; que Borges, en parte, creó.

RINALDI inicia su articulo anulando una denuncia que considera atentatoria a la transparencia de la información, que sólo admite sobre bases de verdad documentada y de sentido de la dignidad humana.

\footnotetext{
- RINAIDI. Angelo. "La premlere vie de Josze Luls Bortes". L'Express Internatiomal, n. ${ }^{\circ} 1824,27$ juin 1986, p. 68-69.

1 Las traduccicres son de la sutors.
} 
La calumnia hasta el final... El 14 de junio, anunciando la muerte, ocurrida en esa misma mañana, del mayor escritor de lengua española y uno de los más importantes de este siglo, en el Informativo de las veinte, cierto individuo de una emisora de televisión afirmaba categóricamente que Jorge Luis Borges había perdido el premio Nobel por nutrir simpatía por generales argentinos. ¿Dónde está la prueba, la declaración, el texto de adhesión? ¿A eso le llaman "servicio público", a una mezcla de ignorancia y de delación, a la ofrenda de mendrugos sobre el atud de un artista, a la difusión de mentiras que siempre dejan residuos en la mente de las personas?

Esta condenación le lleva a denunciar lo que denomina campaña anti-Borges, "urdida con procedimientos stalinistas por la extrema izquierda sudamericana servilmente arrodillada a los pies de Fidel Castro". RINALDI no apoya sus propias conclusiones en "charlas informales", sino que se siente plenamente autorizado a opinar sobre la posición adoptada por el escritor ante um régimen político del cual su país natal acaba de libertarse:

No pudiendo soportarlo, este ciego que vivia en un departamento de dos piezas en Buenos Aires con el único apoyo de una exalumna que benevolentemente se transformó en su secretaria - y con quien se casó el mes pasado - pensó por un momento en refugiarse en Paris.**

A seguir cuenta Rinaldi cómo los esfuerzos de algunos intelectuales y el apoyo personal del presidente Mitterrand, contribuyeron a convertir en realidad los anhelos del octogenario escritor, venciendo las dificultades económicas y las

* El diarlo brasllefio Folha de 5ão Paulo en su edición del 20 de octubre de 1989. a! comentar la concesión del premlo Nobel de este ano otorgado a Camllo José Cela. clta los Julcjos emitidos por la Academta sueca al rechazar a ajeunos llustres escritores (Freud, Tolstoi, Bernard Shaw, Zola, Ibsen Gorkl). J.L.Borges perdió por considerar ia Academla que "un artista nue hay manifestado su lealtad a un dictador. de derecha o de lzqulerda no tlene la necesaria independencla moral para recibir c) premio's ("Jlustrada", página 21. El mismo perídico comenta sobre Cela: "En un lance poco teliz. Allen (Sture Allen, presldente de la Academla Bueca) intentó crcar una jmagén heroica de los sulrimientos del agraclado 'aravemente herido durante la Guerra Civil Espanola'. Sólo que Allen no aclaró que Cela como mercenarlo estuvo a serviclo de las fucrzas naclonalistas del dictador francisco Franco."

Por su parte. C.J. Cela sitún a Jorec Lulz Borges entre los nombres consagrados de la literatura universal que nunca conaulstaron cl premio, sl lado de Marcel Proust y James Joyce, todos "famosos olyldos".

(Cela, Camijo José. Veja, ano 22, n. 44, B nov. 1080, D. 6. Entrevista). 
ridículas objeciones de la burocracia oficial: la edad avanzada del poeta y la legislación de la Previdencia social, por ejemplo...

La solución partió de los hombres de buena voluntad: J. F. Revel tuvo la feliz idea de fundar la Asociación de Amigos de Borges, que con toda presteza Raymond Aron aceptó presidir. El presidente de Francia allanó todos los caminos invitando personalmente al escritor, concediéndole la insignia de la Legión de Honra, en el Palacio Elíseo, y asegurándole durante varias semanas la hospitalidad del gobierno.

En el retrato de Borges que la pluma del cronista traza, un rasgo marcante es la inigualable erudición del escritor ciego, que ninguma relación tiene con la sabiduria vasta $y$ estática, sino que es una energía creadora de sistemas fantásticos gracias a su facultad de establecer correspondencias entre las ficciones aparentemente distintas de los siglos: el concepto de novedad, de originalidad, se ve así relativizado y hasta anulado. "Lo que es bueno no pertence a nadie... a no ser a la lengua y la tradición", A. Rinaldi cita la afirmativa borgesiana, deducida de su creencia en que los hombres, desde el tiempo de las cavernas participan de la redacción del mismo y único libro, reiterando hasta el infinito el asombro de que una noche suceda tan rápidamente a las maravillas del día, del cual sólo subsiste lo que las palabras consiguem retener sobre la página. Por eso el recurso a las mitologias compensatorias, explicativas 0 consoladoras en cuyo interior Borges transitaba a gusto, sin hesitar en considerar a la teologia como una rama de la novela.

Rinaldi revela la sabiduria de Borges, y el enorme radio que abarcan sus intereses de conocimiento, centrados en las letras y las lenguas, y destaca su interpretación de las letras francesas que lo fascinaron desde la primera juventud. Sus conocimientos y su incansable interés por las lenguas del mundo eran la medida de su espíritu universalizante. Vibraba últimamente porque en el verano podría viajar a Noruega, invitado por una universidad, para investigar un dialecto hablado por los antiguos Vikings. Lo estudiaba aún a los 86 años cuando la enfermedad le concedía tregua, cuando no dictaba sus notas a María Kodama para el volumen a publicar en "La Pléiade", cuando no le pedía que leyese cierto trecho del Journal de Gide, o tal fragmento de Montaigne. Murió persuadido de que Cocteau merecia una rehabilitación parcial, de que Verlaine era superior a Rimbaud y de que Mallarmé ya estaba en germen en Boileau. En Ginebra, donde había vivido durante sus estudios pre-universitarios, 
de 1914 a 1921, queria encontrair la musicalidad de las palabras francesas, como lo anunció hace 30 años en un soneto.

Si entre posición ideológico-política y creación artística pueden existir estrechas relaciones, exigir del artista un compromiso explícito, no deja de ser una posición radicalmente sectaria. Rinaldi tacha de sectaria la expectativa de "engagement" como elemento esencial para la obra de arte. En efecto i cómo pedir este compromiso al poeta que nos enseñó a dudar de la realidad, a la sensibilidad que captó al hombre, su mundo y su cultura bajo los amplísimos parámetros de la relativización, al escritor que situó Filosofía y Ciencia en el mismo y privilegiado plano de la creación fantástica? Sectarios serían aquellos que reprochan al genio literario no haberse encasillado bajo determinado rótulo, olvidando que "la misma calidad de su obra contribuye a la defensa de la libertad ensanchando nuestros horizontes", pues "el mundo no sigue siendo más el mismo mundo cuando se han leído los poemas y los cuentos de quien estudió las obras primas de todas las literaturas en su lengua original", en las palabras del articulista.

Cuenta Ángelo RINALDI que Borges, em su último mes de vida, recibió la visita de Marguerite Yourcenar. Estaba en su escondrijo en el corazón de la vieja Ginebra, en su soñado departamento, morada que lo transportaba al pasado y asi negaba el tiempo - el tiempo que Borges sentía como una ilusión entre tantas otras, más allá de sus embates físicos, en un universo donde bastaba tender la lógica hasta sus límites para que la razón oscilara; en ese Universo donde - según le habia enseñado Roger Caillois, su editor y amigo desde 1950 - la naturaleza, no más original que el espiritu cuando éste inventa sus consuelos en el vacio - repite incansablemente las mismas formas y los mismos colores en las piedras.

"- Borges. ¿ cuándo saldrá usted de su laberinto"? preguntó la autora de Adriano, tomando las manos del enfermo entre las suyas.

"- Señora, cuándo los hombres tengan más juicio". Si alguna vez llegan a tenerlo - comenta Rinaldi - es poco probable que alguno exceda en inteligencia al argentino, $y$ su humor, que lo llevaban a dudar de la propia existencia: "Nunca somos tan reales como cuando alguien nos sueña" decia.

Y RINALDI finaliza su crónica en un acto intuitivo de simbiosis intelectual y espiritual con la personalidad que retarta, alzando vuelo desde su lucidez crítica hacia los cielos poéticos: 
"Y tal vez, en efecto, Borges, biblioteca viva, sea la figura colectiva del escritor. El totem forjado por la tribu. $O$, simplificando, la divinidad. Porque Dios, esencialmente, no sabria ser más completo que todos los diccionarios que el autor conocia de memoria". 